\title{
Correlational Study of Life Satisfaction, Caregiving Self-Efficacy and Burden of Caregiving in the Primary Caregivers of Chronic Schizophrenia Patients in Pune
}

\author{
Ms. Sheetal A Lakhani ${ }^{1 *}$, Mrs. Shradha R Sakatkar ${ }^{2}$
}

\section{ABSTRACT}

The prevalence of mental illnesses has been increasing more than ever and the effects are clearly seen in these rising trends. General stress levels of persons are also observing increasing trends accountable in major part to the urbanisation due to rise in competition and other issues. In such urbanised setups, lack of primary care facilities for severe psychiatric patients has lead to additional levels of stress in the relatives who are caregivers of such patients and are leading normally stressful lives. These caregivers are also not aware of the techniques to be used in dealing with patients and this can be an issue especially if patients have aggressive symptoms. Thus, the emotional well-being of the family, especially the primary caregivers, is affected on a large extent.

The aim of the study was to determine the correlation between level of life satisfaction, burden of care and caregiving self-efficacy in the caregivers of schizophrenia patients. Data was collected from 35 primary family caregivers belonging to the middle class of outpatients with chronic (duration of one or more year) schizophrenia in particular private clinics and hospitals of Pune. Zarit's Burden Interview, Revised Scale for Caregiving Self-efficacy (by Steffen et al.) and Life Satisfaction Scale (by Alam \& Srivastava) were used to collect the relevant information. The impact of socio-demographic variables such as duration of illness and employment status of caregiver was also considered. Correlational analysis was used to analyse the data. It was hypothesised that caregiving self-efficacy will be positively correlated with life satisfaction and that burden of care will be negatively correlated with general life satisfaction and finally, that caregiving self-efficacy will be negatively correlated with burden of care. Impactful psychosocial awareness and training programmes can be developed to increase the levels of life satisfaction of the caregivers based on the obtained results.

\footnotetext{
${ }^{1}$ Research Scholar, Psychology Department, Modern College, Pune, India

${ }^{2}$ Assistant Professor, Psychology Department, Modern College, Pune, India

*Responding Author

(C) 2016, S Lakhani, S Sakatkar; licensee IJIP. This is an Open Access Research distributed under the terms of the Creative Commons Attribution License (http://creativecommons.org/licenses/by/2.0), which permits unrestricted use, distribution, and reproduction in any Medium, provided the original work is properly cited.
} 


\section{Correlational Study of Life Satisfaction, Caregiving Self-Efficacy and Burden of Caregiving in the Primary Caregivers of Chronic Schizophrenia Patients in Pune}

Keywords: Caregiving self-efficacy, Burden of caregiving, Life satisfaction, Well-being, primary family caregiver schizophrenia patients.

According to the DSM-IV-TR, Schizophrenia is a persistent, often chronic and usually serious mental disorder affecting a variety of aspects of behaviour, thinking, and emotion. Patients with hallucinations or delusions may be described as psychotic. Thinking may be disconnected and illogical. Peculiar behaviours may be associated with social withdrawal and disinterest (APA, 2000).

Veenhoven defines life-satisfaction as the degree to which a person positively evaluates the overall quality of his/her life as-a-whole. Daniel Hall on the basis of Bandura's concepts defines caregiver self-efficacy as a person's perception of their ability to perform tasks related to caregiving competently, capably, and with control.

The burden of caregiving has been assessed since the 1950s (Yarrow, Clausen \& Robbins, 1955) . Also, the family caregivers are not quite trained in caregiving and this leads to additional burden. Alejandra Caqueo-Urízar et al who performed a search through databases from journals published last decade between 1998 and 2008 reported that decreased QOL may be associated with caregivers' burden, lack of social support, course of the disease and family relationships problems. Magliano et al. (2000) had one interesting finding in one of their follow-up studies on caregiver burden that a reduction of burden was found in relatives with improved coping skills and who received more practical support from their social network. Caregivers' sense of selfefficacy may protect against the adverse effect of caregiver burden on their depressive symptoms (Casado \& Sacco, 2013). One-way causal relationship has also been found between self-efficacy and depressed mood by experimentally inducing self-efficacy in interpersonal skills in caregivers (Stanley and Maddux, 1986 as cited in Steffen et al., 2002)

\section{Hypotheses}

1. In caregivers of chronic schizophrenics, caregiving self-efficacy will be negatively correlated with burden of care.

2. In caregivers of chronic schizophrenics, caregiving self-efficacy will be positively correlated with life satisfaction.

3. In caregivers of chronic schizophrenics, burden of care will be negatively correlated with life satisfaction.

\section{Sample}

Caregivers who were residents of Pune was used as the sample. Caregivers who have resorted to treatment and approached the institutions approached were included. Data from primary caregivers was collected using convenience sampling technique within the age range of 20 to 75

(C) The International Journal of Indian Psychology, ISSN 2348-5396 (e)| ISSN: 2349-3429 (p) | 139 


\section{Correlational Study of Life Satisfaction, Caregiving Self-Efficacy and Burden of Caregiving in the Primary Caregivers of Chronic Schizophrenia Patients in Pune}

years. Caregivers were majorly spouses and parents $(15,15)$ while few were siblings(4) and just one was a ward. 18 of the caregivers were non-working, i.e, retired or unemployed while 17 were working.

\section{Design:}

Correlation research design.

\section{Tools:}

PDS requested demographic data. The Life Satisfaction Scale by Dr. Alam \& Dr. Srivastava comprises of sixty yes/no items related to six areas of life viz. health satisfaction, personal satisfaction, social satisfaction, economic satisfaction, marital satisfaction and job satisfaction whereas a total score is indicative of general life satisfaction. The Revised Scale for Caregiving Self-efficacy by Steffen et al., 2002 consists of 15 items that have to be rated from 0-100 on the basis of how confident or certain the caregiver is in relation to the subject matter of the statements. The Zarit Burden Interview is a 22-item measure of burden that uses a Likert Scale indicating five-point frequency from "Never" to "Always". High score indicates high burden of care. All the scales had sufficient reliability and validity.

\section{RESULTS AND DISCUSSION}

As can be seen in Table 1, The mean age of the caregivers was 47.46 years. The mean values of the group indicate moderation on most of the variables.

\begin{tabular}{|l|r|r|r|r|r|r|r|r|r|r|}
\hline & \multicolumn{1}{l}{ Age } & BOC & RSCE & Health & Personal & Economic & Marital & Social & Job & LSS \\
\hline N & 35 & 35 & 35 & 35 & 35 & 35 & 35 & 35 & 35 & 35 \\
\hline Mean & 47.46 & 40.03 & 719 & 5.09 & 6.23 & 5.49 & 6.06 & 7.31 & 6.57 & 36.69 \\
\hline Median & 48 & 41 & 800 & 5 & 7 & 5 & 7 & 8 & 7 & 39 \\
\hline Mode & 62 & 30 & 250 & 6 & 7 & 5 & 8 & 10 & 5 & 42 \\
\hline S.D. & 14.821 & 20.249 & 417.691 & 1.723 & 1.516 & 1.837 & 2.566 & 2.958 & 1.883 & 7.973 \\
\hline Min & 21 & 3 & 20 & 1 & 3 & 2 & 0 & 0 & 2 & 22 \\
\hline Max & 72 & 78 & 1330 & 8 & 9 & 10 & 9 & 10 & 9 & 47 \\
\hline
\end{tabular}

Table 1

Since the data was not found to meet the assumptions for a parametric test (normal distribution criterion), correlational analysis was performed using Spearman's rho in IBM SPSS version 22.

\begin{tabular}{|l|l|ll|}
\hline & BOC & LS & $.540^{* *}$ \\
\hline CSE & $-.859^{* *}$ & & \\
\hline LS & $-.467^{* *}$ & 1 & 1 \\
\hline
\end{tabular}

Table 2

(c) The International Journal of Indian Psychology, ISSN 2348-5396 (e)| ISSN: 2349-3429 (p) | 140 


\section{Correlational Study of Life Satisfaction, Caregiving Self-Efficacy and Burden of Caregiving in the Primary Caregivers of Chronic Schizophrenia Patients in Pune}

Hypothesis one for the present study, stating that caregiving self-efficacy will be significantly negatively correlated with burden of care was supported. As seen in table 2, Spearman rho correlation coefficient between caregiving self-efficacy and burden of care was found to be -$.859 * *$, meaning that higher the level of caregiving self-efficacy in the caregivers, lower is their level of perceived burden of care. This finding is consistent with the explanations provided by Steffen, Bandura et al (2002) which state that those with a high sense of caregiving efficacy may be protected from the negative consequences of this role by focusing on what they are capable of accomplishing, rather than on their failures. Rather than viewing the demands of caregiving as tasks to be avoided, those with a high sense of caregiving self-efficacy may view them as challenges to be mastered. In short, 'a resilient sense of self-efficacy enables people to endure hardships and persevere against great odds' (Bandura, 1997, p. 22) that are associated with caregiving. Individuals with a low sense of caregiving self-efficacy, on the other hand, are more vulnerable to the stressors of caregiving and are more likely to focus on past failures and doubt their ability to effectively respond to the demands of caregiving. Findings also support this view. However, the correlation is extremely high and questions about relations between the two scales can be and must be raised.

Hypothesis two for the present study, stating that burden of care will be negatively correlated with life satisfaction was also supported. The correlation coefficient as seen in the table is $.467^{* *}$ (table 2), meaning that higher the level of burden of care, lower is the level of life satisfaction. Abundant studies report negative correlation between burden of care and quality of life in caregivers of schizophrenia patients. This can be attributed to family issues and disturbances due to the patient's illness, social embarrassment due to behaviour or economic costs of treatment. Excessive involvement with the patient burdens the caregiver highly which in turn affects life satisfaction. Lower levels of caregiving burden may not cause such disturbances.

Hypothesis number three of the present study, stating that caregiving self-efficacy will be significantly positively correlated with life satisfaction in general was also supported. The correlation coefficient was found to be $.540^{* *}$ (table 2) meaning that higher the level of caregiving self-efficacy, lower is the level of life satisfaction. Depressive symptoms in the study of Steffen et al., 2002 were found to be more prevalent in the caregivers with low caregiving self-efficacy. One-way causal relationship has also been found between self-efficacy and depressed mood by experimentally inducing self-efficacy in interpersonal skills in caregivers (Stanley and Maddux, 1986 as cited in Steffen et al., 2002).

Interpretations of effects of demographic variables were as follows:- 3 out of 23 female patients had a late onset(after age 40 years) or unnoticed/ undiagnosed previous onsets. 21 out of 35 patients were reported to be married, 15 out of which were taken care of by their own spouses. 5 out of all the caregivers stayed only with the patients or along with young children or senior 


\section{Correlational Study of Life Satisfaction, Caregiving Self-Efficacy and Burden of Caregiving in the Primary Caregivers of Chronic Schizophrenia Patients in Pune}

citizens unable to help and had no other help from home. BOC for these cases were in the higher range whereas the CSE and LS were in the low to average range. Only one out of these had intentions to admit the patient to the rehabilitation centre in the near future. He was 62 himself and stayed with his mother who was over eighty years of age and the daughter (patient) who was 25 years old. Retired caregivers showed high caregiving self-efficacy except for the case noted above. ( $>950$ out of 1500). Highest burdens (>65 out of 88) were reported by males taking care of females or males followed by females taking care of females. This reflects Indian scenario.

\section{APPLICATIONS IMPLICATIONS}

Given the magnitude of services provided and the sacrifices made by caregivers, caregiver burden has been recognized as a serious public health concern. Additionally, caregivers often feel disappointed and dissatisfied with the information and cooperation offered by psychiatric institutions. (Jungbauer et al., 2002). The family caregivers are not quite trained in caregiving and this leads to additional burden. The findings can thus be used in implementing programs to address the needs of the caregivers of schizophrenia patients.

Caregiver burden is important, prevalent, and preventable. The question that the present study tries to answer is 'how'. Psycho-educational programmes can be developed that focus on raising the levels of caregiving self-efficacy. These programmes can also provide them with information about treatment modes and their advantages, side effects and disadvantages. More stress can be given to the correct ways of coping and of looking at the problem in a rational manner rather than emotional. Caregiver burden can be reduced to optimum in a way that life satisfaction is not affected at large- attitudes towards mental illnesses, patients and treatment approaches can be corrected. Life satisfaction can be increased by working on known stressors. Early intervention could result in reduction in morbidity and better quality of life for the patients and their families. Directions for further research.

First and foremost, using larger sample sizes, research can be replicated. Pre and post-test research can be conducted using intervention programmes decided on the basis of the results of this study. A study could also assess for the mediating role of caregiving self-efficacy and burden of care in life satisfaction as a whole. Regression analysis in cohort studies can be done to predict life satisfaction in newer cases of mental illness and to determine the prognosis and the types of interventions to be used. Similar research can be conducted in other mental disorders that are severe in nature and may imply caregiver burden. Comparisons can be made between the various serious mental illnesses on the correlations between the factors Longitudinal research may provide deeper insight to the real picture and fluctuations during the different phases in the course of illness. Other qualitative variables and quantitative variables such as the age of the caregiver, severity of illness, gender of both the caregiver and the patient, anticipated outcomes of the caregivers etc. could be considered. Lastly, such a study can be extended to other 


\section{Correlational Study of Life Satisfaction, Caregiving Self-Efficacy and Burden of Caregiving in the Primary Caregivers of Chronic Schizophrenia Patients in Pune}

geographical locations especially, rural locations to better understand differences and similarities. Cross-cultural research could be conducted to establish certainty.

\section{CONCLUSION}

On the basis of the findings of the study the following conclusions can be drawn:-

1. Caregiving self-efficacy was found to be negatively correlated with perceived burden of care in primary caregivers of chronic schizophrenia patients.

2. Caregiving self-efficacy in primary caregivers of chronic schizophrenia patients was found to be positively correlated with life satisfaction.

3. Burden of care was found to be negatively correlated with life satisfaction in primary caregivers of chronic schizophrenia patients.

\section{Acknowledgments}

The author appreciates all those who participated in the study and helped to facilitate the research process.

\section{Conflict of Interests}

The author declared no conflict of interests.

\section{REFERENCES}

Alam, Q. G. \& Srivastava R.(1996): Life satisfaction scale, construction and standardization. National psychological Association, Agra.

Alam, Q. G. \& Srivastava R.(2001):Manual for Life satisfaction scale. National Psychological Association, Agra.

American Psychiatric Association(2013) Diagnostic and statistical manual of mental disorders: DSM-5 Washington, D.C: American Psychiatric Association.

Caqueo-Urízar, A.; Gutiérrez-Maldonado, J. \& Miranda-Castillo,(2009) C.

Cassado, B. L \& Sacco, P. (2013) The Role of Caregiver Self-Efficacy in the Caregiving Stress Process Among Caregivers of Older Korean Americans with Dementia. Retrieved from:https://sswr.confex.com/sswr/2013/webprogram/Paper18826.html

Foldemo, A ; Gullberg, M.; Ek, Anna-Christina \& B (2005) Quality of life and burden in parents of outpatients with schizophrenia. Retrieved From: http://www.divaportal.org/smash/record.jsf? pid=diva2\%3A244736\&dswid=3081

Jungbauer J \& Angermeyer M.C.(2002) Living with a schizophrenic patient: a comparative study of burden as it affects parents and spouses. Retrieved From: http://www.ncbi.nlm.nih.gov/pubmed/12108136

Kaplan BJ, Kaplan VA. Kaplan and Sadock's Synopsis of Psychiatry: Behavioral Sciences/Clinical Psychiatry. 9th ed. Philadelphia, Pa: Lippincott Williams \& Wilkins. 


\section{Correlational Study of Life Satisfaction, Caregiving Self-Efficacy and Burden of Caregiving in the Primary Caregivers of Chronic Schizophrenia Patients in Pune}

Kheng, S.B. (2005) The impact of schizophrenia: the burden of Care. Retrieved from: http://scholarbank.nus.edu.sg/bitstream/handle/10635/15000/full\%20thesis\%20final.pdf? sequence $=1$

Quality of life in caregivers of patients with schizophrenia: A literature review.

Rammohan, A.; Rao, K. \& Subbakrishna, D.K Burden (2002) and coping in caregivers of persons with schizophrenia. Retrieved From:- . . http://www.ncbi.nlm.nih.gov/pmc/articles/PMC2954392

Retrieved From: http://www.ncbi.nlm.nih.gov/pmc/articles/PMC2749816/

Steffen, A. M., McKibbin, C., Zeiss, A. M., Gallagher-Thompson, D. and Bandura, A.(2002). The revised scale for Caregiving Self-efficacy.: Reliability and Validity Studies. The Journals of Gerontology : Psychological Sciences, 57, 74-86. Retrieved from: http://www.uky.edu/ eushe2/BanduraPubs/Bandura2003JG.pdf

How to cite this article: S Lakhani, S Sakatkar (2016), Correlational Study of Life Satisfaction, Caregiving Self-Efficacy and Burden of Caregiving in the Primary Caregivers of Chronic Schizophrenia Patients in Pune, International Journal of Indian Psychology, Volume 3, Issue 4, No. 68, ISSN:2348-5396 (e), ISSN:2349-3429 (p), DIP:18.01.205/20160304, ISBN:978-1-36539398-3 